\title{
Effect of Meditation on Ultraweak Photon Emission from Hands and Forehead
}

\author{
Eduard P.A. Van Wijk ${ }^{a}$ John Ackerman ${ }^{c}$ Roeland Van Wijk ${ }^{a, b}$ \\ a International Institute of Biophysics, Neuss, Germany \\ b Utrecht University, The Netherlands \\ ${ }^{c}$ Cottage Hospital, Santa Barbara, CA, USA
}

\section{Key Words}

Ultraweak photon emission - Biophotons - Skin - Meditation . Fano factor . Free radicals

\section{Summary}

Background: Various physiologic and biochemical shifts can follow meditation. Meditation has been implicated in impacting free radical activity. Ultraweak photon emission (UPE, biophoton emission) is a constituent of the metabolic processes in a living system. Spectral analysis showed the characteristics of radical reactions. Objectives: Recording and analysing photon emission in 5 subjects before, during and after meditation. Methods: UPE in 5 subjects who meditated in sitting or supine positions was recorded in a darkroom utilising a photomultiplier designed for manipulation in three directions. Results: Data indicated that UPE changes after meditation. In 1 subject with high pre-meditation values, UPE decreased during meditation and remained low in the postmeditation phase. In the other subjects, only a slight decrease in photon emission was found, but commonly a decrease was observed in the kurtosis and skewness values of the photon count distribution. A second set of data on photon emission from the hands before and after meditation was collected from 2 subjects. These data were characterised by the Fano factor, $F(T)$, i.e. variance over mean of the number of photoelectrons observed within observation time $\mathrm{T}$. All data were compared to surrogate data sets which were constructed by random shuffling of the data sets. In the pre-meditation period, $F(T)$ increased with observation time, significantly at time windows $>6 \mathrm{~s}$. No such effect was found after meditation, when $F(T)$ was in the range of the surrogate data set. Conclusions: The data support the hypothesis that human photon emission can be influenced by meditation. Data from time series recordings suggest that this non-invasive tool for monitoring radical reactions during meditation is useful to characterise the effect of meditation. Fano factor analysis demonstrated that the time series before meditation do not represent a simple Poisson process. Instead, UPE has characteristics of a fractal process, showing long-range correlations. The effect of meditation waives out this coherence phenomenon, suggesting a weaker and less ordered structure of UPE. In general, meditation seems to influence the complex interactions of oxidative and anti-oxidative reactions which regulate photon emission. The reason for the statistical changes between pre- and post-meditation measurements remains unclear and demands further examination.

\section{Schlüsselwörter}

Ultraschwache Lichtstrahlung · Biophotonen - Haut · Meditation . Fano-Faktor . Freie Radikale

\section{Zusammenfassung}

Hintergrund: Verschiedene physiologische und biochemische Veränderungen können durch Meditation ausgelöst werden. Meditation beeinflusst möglicherweise auch die Aktivität von freien Radikalen. Die ultraschwache Photonenemission (UPE, biophoton emission) ist ein Bestandteil der metabolischen Prozesse in lebenden Systemen. Spektralanalysen zeigten die Merkmale der Radikalreaktionen. Zielsetzung: Erfassen und Analysieren der UPE bei 5 Personen vor, während und nach der Meditation. Methoden: Die UPE wurde bei 5 Personen, die in sitzender oder liegender Haltung meditierten, mit einem in drei Richtungen beweglichen Photomultiplier in einer Dunkelkammer aufgenommen. Ergebnisse: Die Daten zeigten, dass sich die UPE nach der Meditation veränderte. Bei einer Person, die vor der Meditation hohe UPEWerte hatte, nahm die UPE während der Meditation ab und blieb niedrig in der Phase nach der Meditation. Bei den anderen Personen war die Abnahme der Photonenemission nur schwach, aber im Allgemeinen nahmen die Kurtosis und die Schiefe der Photonenverteilung ab. Ein zweiter Datensatz über die Photonenemission von den Händen vor und nach der Meditation wurde bei zwei Personen gesammelt. Diese Daten ließen sich charakterisieren durch den Fano-Faktor F(T), also als Varianz über den Mittelwert der Anzahl der Photoelektronen, die während einer bestimmten Zeitspanne beobachtet wurden. Alle Daten wurden mit einem Satz von Zufallsdaten verglichen, der durch eine zufällige Mischung der empirischen Daten zustande kam. Vor der Meditation nahm $F(T)$ bei Zeitfenstern $>6$ s über die Beobachtungszeit signifikant zu. Dieser Effekt war nach der Meditation nicht sichtbar. Hier lag F(T) im Bereich der Zufallswerte. Schlussfolgerungen: Die Daten stützen die Vermutung, dass menschliche Photonenemission durch Meditation beeinflusst werden kann. Eine Zeitreihenanalyse der Daten legt nahe, dass dieses nichtinvasive Werkzeug hilfreich ist, um die Reaktion freier Radikale während der Meditation zu beobachten und diesen Meditationseffekt genauer zu beschreiben. Die Analyse des Fano-Faktors zeigte, dass die Zeitreihenanalyse vor der Meditation kein einfacher Poissonprozess ist. Stattdessen hat die UPE alle Merkmale eines fraktalen Prozesses und zeigt weit reichende Korrelationen. Der Effekt der Meditation verhindert dieses Kohärenzphänomen und legt deshalb eine schwächere und weniger geordnete Struktur der UPE nahe. Allgemein scheint also Meditation die komplexen Interaktionen der oxidativen und antioxidativen Reaktionen zu beeinflussen, die der Photonenemission zugrunde liegen. Die Ursache für die statistischen Veränderungen zwischen Vor- und Nachmeditationsmessungen ist noch unklar und erfordert weitere Untersuchungen.

\begin{tabular}{ll}
\hline KARGER & ๑ 2005 S. Karger GmbH, Freiburg \\
Fax +49 7614520714 & Accessible online at: \\
$\begin{array}{l}\text { E-mail Information@Karger.de } \\
\text { www.karger.com }\end{array}$ & www.karger.com/fkm
\end{tabular}




\section{Introduction}

Meditation refers to a family of techniques that share a conscious attempt to not dwell on discursive, ruminating thoughts but rather to focus attention in a non-analytical way [1]. People who meditate often develop their own mix of techniques. These can embrace mindfulness meditation, concentrative meditation, passive breathing exercises, yoga stretching, imagery, and autonomic training. In general, it is difficult to estimate exactly which part of the technique is responsible for the meditation experience. One definition of meditation experience is labelled 'unity', i.e. the loss of difference between subject and object [2]. Various physiologic and/or biochemical shifts can follow meditation. Short-term physiologic effects during and immediately after meditation have been described by various authors for more than 30 years [3]. Davidson et al. [4] demonstrated alterations of both left anterior activation and antibody titres to influenza vaccine in subjects who meditated 45 min daily over a 6 -week period. In addition, these people met weekly for up to $3 \mathrm{~h}$, and participated in a silent 7-h retreat in week 6. Long-term effects in subjects with chronic diseases were reported $[5,6]$. Transcendental meditation has been implicated in impacting free radical activity as demonstrated by lower blood peroxide levels [7]. This observation suggests that human photon emission can be influenced by meditation.

In the field of biophotonics, highly sensitive photomultiplier devices have been developed to non-invasively study ultraweak photon emission (UPE, biophoton emission) from the human body [8]. UPE is a constituent of the metabolic processes of any living system. Intensity fluctuations reflect the dynamic interplay of elementary biochemical reactions (weak molecular and supra-molecular interactions) under physiological conditions. Recently, the authors undertook a multi-set recording protocol of spontaneous human UPE, using a photomultiplier especially designed to record very low emission rates. Spectral analysis showed the characteristics of radical reactions through lipid peroxidation [9].

Early measurements showed no clear effect of any 'energetic technique' on the intensity or spectral composition of UPE [8]. Dobrin et al. [10,11] compared UPE in subjects who intentionally tried to influence emission to that in controls. The rather simple equipment used in their study easily explains why the authors did not yield any clear answer. Later, Nakamura et al. [12] studied the influence of Qigong on biophoton emission from the fingertips. In one subject, UPE increased during qi emission. In the other subjects, however, no such dependency between consciousness and biophoton emission was observed. Vekaria [13] investigated the influence of intention on photon emission from the hands and found that the mean photon count decreased in the intention mode. Not all subjects could influence photon emission with equal success, though. Analyses revealed that there was an individual variation among as well as within subjects.
The present study is the first to examine with photon count statistics of hands and forehead changes in the characteristics of the optical radiation field due to meditation in order to find out whether there is any effect. It was not our goal to identify a particular type or component of meditation as most effective.

\section{Methods}

\section{Subjects}

Subjects were 5 fellow scientists who joined this research programme out of their personal interest. All subjects, 2 females and 3 males, aged 42-65 years, reported to be healthy and were non-smokers. Each had had experience with meditation for at least 15 years although they used different techniques. Four subjects (subjects 2-5) practiced daily.

\section{Meditation Techniques}

The meditation techniques used were

- a particular form of Zen meditation focusing on a monosyllable sound while observing breathing. This approach is akin to mindfulness meditation; i.e., attention is being held in the present utilising the monosyllable to maintain focus (subject 1);

- phi-damped breathing wherein the amplitude and frequency of breathing decreases until zero breathing is attained, which then initiates repetition of the cycle (subjects 2 and 3);

- transcendental meditation (subject 4);

- a personal rendition of transcendental meditation comprising two parts. The first part: saying a monosyllable while exhaling (three breathing cycles). The second part: not thinking about anything and letting one's mind drift. Alternating between parts one and two until a physical sign is experienced (subject 5).

\section{Darkroom with Photomultiplier Device}

A special darkroom and photon counting device were used to record UPE of the subjects [cf. 9]. Walls and ceiling of that darkroom were covered with black matt paint. It had commonly a temperature of $20^{\circ} \mathrm{C}$, and was vented. The darkroom had a bed inside and subjects could be easily measured in lying or sitting position. The darkroom was built inside a control room without windows, and separated by a light tight door. The control room contained the electrical equipment and a remote computer system for the photomultiplier and its steering system. Subjects used the control room for adaptation. To this end it was illuminated with dim red light. The photomultiplier (EMI 9235 QB, selected type) used could be manipulated in 3 directions. It was a 52-mm diameter, especially selected, low noise, end window photomultiplier that was mounted in a sealed housing under vacuum with a quartz window. An additional ring at the front of the photomultiplier tube allowed to measure a 9-cm-diameter area at a fixed distance from the body $(70 \mathrm{~mm})$. This front ring was vented inside in order to avoid condensation of moisture at the quartz window and the shutter. The photomultiplier had a spectral sensitivity range of 200-650 nm. It was maintained at a low temperature of $-25^{\circ} \mathrm{C}$ in order to reduce the dark current (electronic noise). During the experimental period, the average dark current (electronic noise) was $4.9 \pm 0.3$ counts per second (cps).

\section{Protocol}

Subjects were introduced to the control room and shielded from ambient light for at least $1 \mathrm{~h}$ before starting the experiment. Thus, delayed photon emission due to previous exposure to light was prevented [cf. 9]. During that time subjects were informed about the experiment. After $1 \mathrm{~h}$ the subjects entered the darkroom. At the beginning of the hand recordings, subjects were instructed to find a comfortable sitting position similar to that 
Table 1. Photon emission before and after meditation

\begin{tabular}{|c|c|c|c|c|c|c|c|}
\hline \multirow{2}{*}{$\begin{array}{l}\text { Subject } \\
\text { (recording) }\end{array}$} & \multirow[t]{2}{*}{ Body area } & \multicolumn{3}{|c|}{ UPE before meditation, cps } & \multicolumn{3}{|c|}{ UPE after meditation, cps } \\
\hline & & $\mathrm{M} \pm$ s.e.m. & kurtosis & skewness & $\mathrm{M} \pm$ s.e.m. & kurtosis & skewness \\
\hline 1 & Hand & $46.2 \pm 0.4$ & 1.0 & 0.4 & $24.9 \pm 0.3$ & 1.1 & 0.6 \\
\hline 1 & Forehead & $10.0 \pm 0.2$ & 3.0 & 1.2 & $9.9 \pm 0.2$ & 1.8 & 1.0 \\
\hline $2(1)$ & Hand & $14.2 \pm 0.2$ & 3.4 & 1.1 & $12.1 \pm 0.2$ & 1.4 & 0.9 \\
\hline $2(2)$ & Hand & $16.0 \pm 0.2$ & 3.1 & 1.2 & $16.1 \pm 0.2$ & 1.3 & 0.8 \\
\hline $3(1)$ & Hand & $9.5 \pm 0.2$ & 2.2 & 1.2 & $8.5 \pm 0.2$ & 1.2 & 0.9 \\
\hline $3(2)$ & Hand & $11.4 \pm 0.2$ & 1.2 & 0.9 & $12.1 \pm 0.2$ & 0.5 & 0.6 \\
\hline $4(1)$ & Hand & $15.4 \pm 0.2$ & 6.3 & 1.5 & $14.7 \pm 0.2$ & 0.9 & 0.8 \\
\hline $4(2)$ & Hand & $19.2 \pm 0.2$ & 0.6 & 0.5 & $19.1 \pm 0.2$ & 0.3 & 0.5 \\
\hline $5(1)$ & Hand & $19.1 \pm 0.3$ & 4.7 & 1.4 & $17.9 \pm 0.3$ & 0.3 & 0.5 \\
\hline $5(1)$ & Forehead & $14.8 \pm 0.3$ & 9.4 & 1.7 & $14.2 \pm 0.3$ & 1.9 & 1.0 \\
\hline $5(2)$ & Hand & $16.3 \pm 0.3$ & 1.0 & 0.8 & $15.3 \pm 0.3$ & 0.7 & 0.6 \\
\hline $5(2)$ & Forehead & $12.0 \pm 0.2$ & 1.1 & 0.9 & $11.4 \pm 0.2$ & 0.9 & 0.9 \\
\hline
\end{tabular}

utilised during meditation. Subjects were in the supine position when their forehead was recorded. The photomultiplier was then positioned; the door was closed, and the session began.

During the 10-min adaptation period the background (electronic noise) of the photomultiplier was recorded. After adaptation, photon emission was recorded in three periods of $10 \mathrm{~min}$ each:

- before meditation; the subjects performed a simple cognitive task (for example, counting backwards from 1,000);

- during meditation; each subject used his/her approach to meditate; - after meditation; the subjects again performed their cognitive task.

In the first series with all 5 subjects, each 10 -min period was divided to 600 intervals of $1 \mathrm{~s}$, and for Fano factor analysis (in 2 subjects) to 6,000 time intervals of $100 \mathrm{~ms}$. After the experimental session, background measurements were recorded to ensure that background values had not changed.

\section{Data Analysis}

Statistica 6.0 was used for basic statistical analyses of photon count data. In addition, we determined the photon count distribution with increasing time window for observing photon emission. This was found to be very helpful to analyse the random or deterministic character of fluctuations in action potentials [14-16] and photon count [13, 17]. Furthermore, we determined the Fano factor $\mathrm{F}(\mathrm{T})$, defined as the variance divided by the mean number in a time window $\mathrm{T}$ :

$\mathrm{F}(\mathrm{T})=$ Variance $\left[\mathrm{N}_{\mathrm{i}}(\mathrm{T})\right] /$ mean $\left[\mathrm{N}_{\mathrm{i}}(\mathrm{T})\right]$

where $\mathrm{N}_{\mathrm{i}}(\mathrm{T})$ is the number of events in the $\mathrm{i}^{\text {th }}$ time window of length $\mathrm{T}$.

The Fano factor curve is constructed by plotting $\mathrm{F}(\mathrm{T})$ as a function of the window size $\mathrm{T}$ on a $\log -\log$ scale. For a total block of $\mathrm{T}_{\max }=600 \mathrm{~s}$ with sampling times of $100 \mathrm{~ms}$, T was varied from a minimum of $100 \mathrm{~ms}$ to a maximum of $\mathrm{T}_{\max } / 6$, so that at least 6 non-overlapping windows of $100 \mathrm{~s}$ were used for each measure of the Fano factor (index i counts the number of windows).

From a theoretical perspective, it can be shown that for a random process in which fluctuations in photon counts are uncorrelated, $F(T)$ is 1 for all window sizes $[14,15]$. For a periodic process, the variance decreases and $\mathrm{F}(\mathrm{T})$ approaches 0 as the time window is increased. For a fractal process, $F(T)$ increases as a power of the window size and may reach values $>1$. The power-law relationship appears as a straight line with a positive slope $\alpha$. Alpha, the scaling exponent, is the power to which fluctuations in counts on one time scale are proportional to those on larger time scales. Linear regression is used to calculate $\alpha$. Whether the calculations for the Fano factor curve are correct and truly reflect a fractal process and thus long-range correlations of events was tested by constructing surrogate data sets in which we used sets of randomised data. For this purpose, random numbers were assigned to the photon counts in the original time se- ries and then the random numbers were sorted by size. In the experimental situation, only data deviating from the surrogate data set were considered as meaningful deviations and used for later evaluations.

\section{Results}

\section{Photon Emission before and after Meditation}

In another study, our group found that different subjects emit at different intensities depending on the body location [9]. The present study focuses on intensity alterations of photon emission within one and the same body location of a given subject. Table 1 illustrates means and corresponding standard errors of photon emission in the five subjects before and after meditation. Mean, standard error of the mean, kurtosis and skewness were calculated from 10-min recordings (600 measurements of $1 \mathrm{~s})$. In subjects 1 and 5, UPE was recorded both from hand and forehead; subject 5 was recorded twice. In subject 1, photon emission from the hand before meditation was more than twice as intense as in the other subjects. Figure 1 illustrates the results of recording hand photon emission in subject 1 over time before, during and after meditation. The intensity of photon emission in the pre-meditation period was approximately $46 \mathrm{cps}$ followed by an intensity decrease to $25 \mathrm{cps}$ in the post-meditation period. Taken into account electronic background, meditation involved a 50\% continual decline of emission intensity. In the post-meditation period, photon emission did not decrease further; it remained low, without any sign of recovery within the recording period. This behaviour, i.e., a stable, lower intensity after the 10 min post-meditation was also observed in the other subjects. However, in the latter subjects, photon emission intensity was in most cases only slightly decreased. The frequency distributions of photon counts were characterised by skewness and kurtosis values (table 1). The kurtosis, a parameter for the peakedness of a distribution of photon counts, and the skewness, a parameter of non-symmetry of a distribution, commonly decreased after 
meditation. This suggests that further statistical characterisation of the emission process may provide more insights.

\section{Fano Factor}

In order to further distinguish the influence of meditation on photon emission of human beings, Fano factor analysis was applied. For this analysis, more refined recordings at shorter intervals were made: recording $10-\mathrm{min}$ pre- and post-meditation periods with 6,000 time intervals of $0.1 \mathrm{~s}$ increased the window size range. Two subjects (subjects 2 and 3 ) were able to contribute with 6 meditation sessions each to this series of recordings. The data of each pre- and post-meditation session were analysed according to a standard procedure. For a recording time of $600 \mathrm{~s}\left(\mathrm{~T}_{\max }\right)$, we used $\mathrm{T}_{\max } / 6$ as the largest time scale for a data block so that with 6,000 data points of $0.1 \mathrm{~s}$, at least 6 non-overlapping windows of 1,000 data points (equivalent to $100 \mathrm{~s}$ window time) were used for $\mathrm{F}(\mathrm{T})$. We calculated $\mathrm{F}(\mathrm{T})$ values for 13 different window sizes between $0.1 \mathrm{~s}$ and $100 \mathrm{~s}$. Figures 2 and 3 present the mean (s.e.m.) Fano factor values at the different window sizes for pre- and postmeditation of each subject together with the results of the surrogate data set. In the pre-meditation period, the 2 subjects showed Fano factor values $>1$ with a marginal increase at window sizes between 0.1-6 s. At window sizes between 6-100 s the Fano factor increased more evidently with window size, and rose significantly above the surrogate data set. The increase in Fano factor with window size after meditation was lower than before meditation and never rose above the level of the surrogate data set.

In the pre-meditation period, the scaling exponent $\alpha$ was calculated by linear regression over the range of window sizes between $6-100 \mathrm{~s}$ as $0.23 \pm 0.04$ and $0.19 \pm 0.06$ for subjects 2 and 3, respectively. A similar calculation for the post-meditation period showed $\alpha$ as $-0.01 \pm 0.06$ and $-0.05 \pm 0.07$, respectively. Scaling exponents of pre- and post-meditation were significantly different in both subjects $(\mathrm{p}<0.05)$.

\section{Discussion}

In the present study, meditation was used as the independent variable. Yet, it must be noted that different techniques or combinations of techniques can be applied, and that meditation is not easy to quantify. The subjects participating in the study had learned different meditation techniques or developed a unique combination technique. Four out of 5 subjects practiced daily. The dependent variables in the present study were the intensity of photon emission, its distribution parameters of kurtosis and skewness, and the Fano factor.

The presented pre-meditation data illustrate that the intensity of photon emission may differ between subjects and between body locations, ranging between 46 and $8 \mathrm{cps}$. These values include background (electronic noise) of approximately $5 \mathrm{cps}$. The previous multi-site recording study demonstrated that

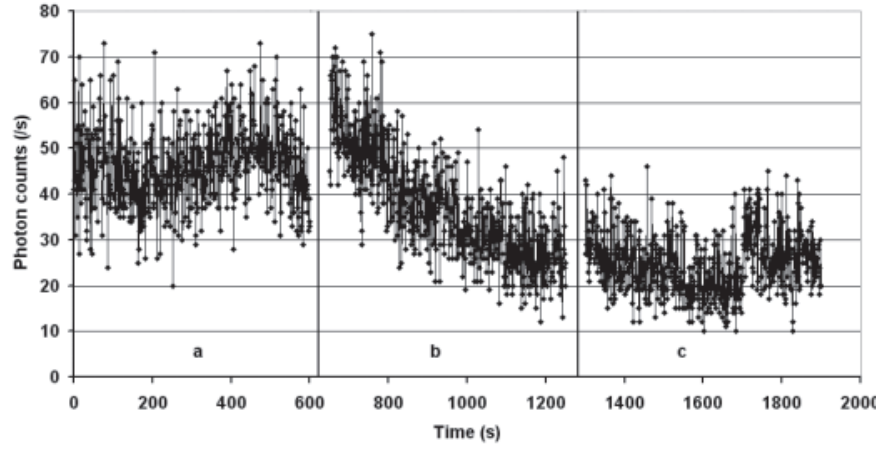

Fig. 1. Spontaneous emission from the hand a before $(0-600 \mathrm{~s})$, b during (650-1,250 s), and c after (1,300-1,900 s) meditation (subject 1).

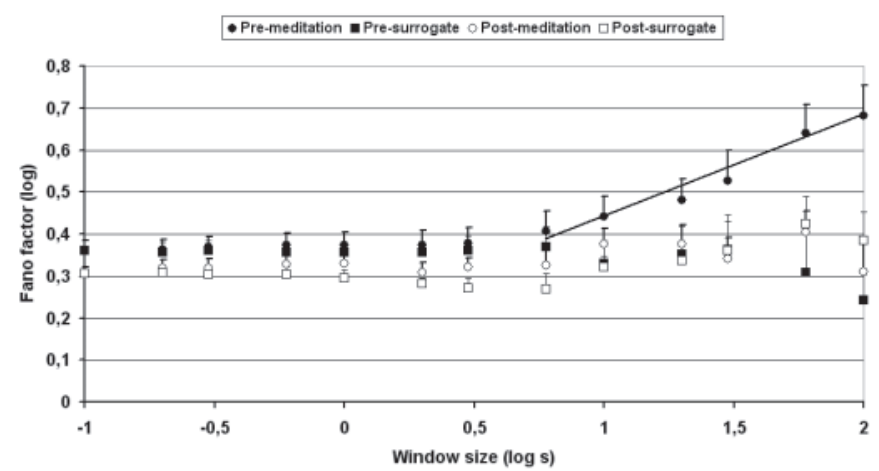

Fig. 2. Mean (s.e.m.) Fano factor values vs. observation time (window time) for UPE from the hands of subject 2 before and after meditation as compared to surrogate data.

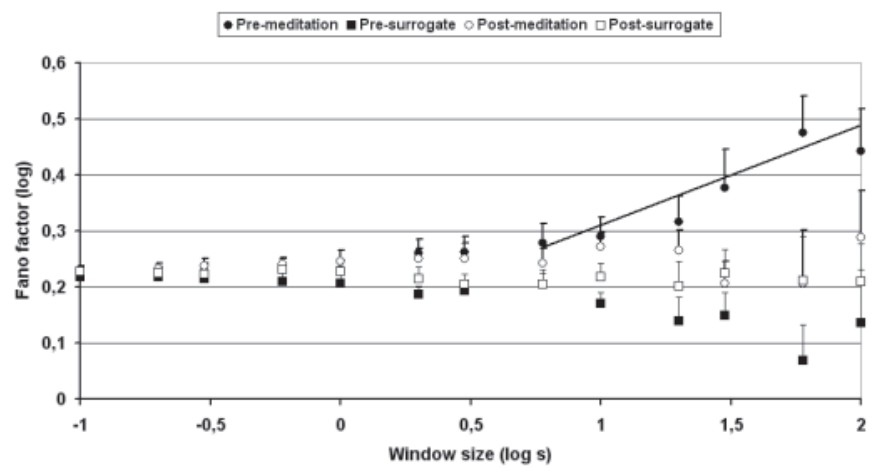

Fig. 3. Mean (s.e.m.) Fano factor values vs. observation time (window time) for UPE from the hands of subject 3 before and after meditation as compared to surrogate data.

lowest emissions around 8-9 cps tend to be observed in the morning and on the thorax-abdominal region [9]. Photon emission increases in the course of the day depending on the body location. This increase is relatively small in the lower extremities; thorax-abdominal region does not change. Photon emission from the hands reflects a strong tendency to increase. In general, photon emission is higher and shows more dynamic over hands and forehead [9]. This is why these two regions were chosen for the present study. 
It is interesting that the low levels of hand photon emission were recorded in those 4 subjects that practiced meditation daily. The data of subject 1 , who did not meditate regularly, reflected a relatively high intensity of photon emission and a large effect of meditation on intensity. In subjects 2-5 effects of meditation were mainly observed in the skewness and kurtosis of the photon count distribution. Such an effect of meditation was not observed in subject 1 , though. Further studies are required to establish a possible inverse relation between meditation practice and intensity and distribution parameters of photon counts.

The conditions for recording were analysed to make sure that changes in UPE were not due to external factors such as temperature and humidity. Temperature and humidity did not change during the 45-min period of measurement. A systematic decrease of UPE due to long-term delayed luminescence could also be ruled out. The procedure, including a 1-h dark adaptation of the subject and 10-min recording periods, revealed only small differences between the average photon emissions of two consecutive recording periods [9]. Control data sets showed that two consecutive measurements, differed on average by $1.6 \%$, without any systematic increase or decrease.

We can speculate about the physiological implications of meditation on emission intensity. From a biochemical point of view, the emission of light from the hands results from relaxation of excited states. Spectral analysis gave first insights into the underlying molecular changes [9]. The wavelength of hand emission, corresponding to the UV and visible (200-650 nm) spectral range of the photomultiplier demonstrated that major intensity is emitted in the $470-570 \mathrm{~nm}$ range. It suggested reactions involving singlet oxygen, its dimers, and excited carbonyls [18-20]. Such reactions and emission spectra depend on complex interactions of oxidative and anti-oxidative processes [21].

Our previous data on hand photon emission have shown that emission depends on the supply of blood, probably on oxygen supply [9]. Thus, it can be speculated that rhythmic pulsations of blood in the cardiovascular system as well as breathing rhythm influence in a complex manner oxygen supply of the hand over time. Such processes may lead to time series of photon emission that look random at first inspection. With the techniques of non-linear analyses it may be possible to reveal underlying deterministic dynamics. Studies of cardiovascular and neural systems were the first to be subjected to non-linear methods of analysis, demonstrating that the time series that represent fluctuations in heart rate and neuron firings are not at all random, but instead can be completely deterministic. Such time series which show features of scale invariance are described as fractal or chaotic [16].

In the present study, we applied the Fano factor time curve $\mathrm{F}(\mathrm{T})$ that was utilised before by Teich $[14,15]$ and Gebber et al. $[22,23]$ to study the statistical properties of action potentials. F(T) was used by Vekaria [13] and Kobayashi and col- leagues [17] to evaluate UPE data. The increase in $\mathrm{F}(\mathrm{T})$ occurs because rare clusters of high and low photon counts are more apt to be found as more and more data are collected. Such clustering has been considered characteristic of a fractal process $[14,15]$.

The analysis of Fano factors with data from the photon emission showed that the pre-meditation data do not represent a simple Poisson process. If the photon counts represented a Poisson process, that is, if they occurred with equal probability per unit time, the Fano factor would approach unity. In the present paper, we report values $>1$, even at a short time window of $0.1 \mathrm{~s}$ where they are in the range of the surrogate data. A possible explanation is the variance of the electronic noise of the photomultiplier. The Fano factor of incident light must be deduced by correcting for the variance of the dark component. Such procedure is currently under investigation (Van Wijk et al., paper submitted).

In the pre-meditation period for longer time windows ( $>6 \mathrm{~s})$, increases of the Fano factor approximated a power log scaling. Within this range, the curve for the real data clearly deviated from the superposed curves for 12 surrogate data blocks. For window sizes $<6 \mathrm{~s}$, the values of $\mathrm{F}(\mathrm{T})$ for the real data were approximately the same as those of the surrogate blocks. Therefore, the power-law relationship can be attributed to longrange correlations among photons, corresponding to the significant increase of $\mathrm{F}(\mathrm{T})$ in window length $\geq 6 \mathrm{~s}$.

The log scaling behaviour is considered the signature of a fractal process [16]. Thus, as more data were collected, the variance increased, possibly because of photon clustering in the emission process, and these clusters become increasingly manifest over longer time windows. Such clustering has not been reported for human photon emission before. However, such a behaviour has been reported before for the Fano factor of photon time series in the initial stages of cell proliferation of marine luminescent bacteria [17].

The dynamic process of photon emission suggests its modelling as non-linear dynamic system. It is evident that much research is still needed in modelling the reaction schemes in the oxidative and anti-oxidative reactions regulating singlet oxygen and photon emission.

It is still unclear how meditation lowers statistical measures like kurtosis, skewness of UPE data. The Fano factor F(T) shows that especially the time window $>6 \mathrm{~s}$ is affected. The Fano factor data suggest that a different pattern occurs following meditation, probably due to a decrease in photon clustering in photon emission. In the light of our discussion this results from (a) differences in the tuning of oxidative and antioxidative processes that regulate free radical levels and thus photon emission; (b) the dynamics of the blood flow in the capillaries which supply the necessary oxygen to the tissue, and consequently modulates the processes mentioned in (a). The whole setting of the different types of meditation lowered the deterministic order of the UPE as expressed via $\mathrm{F}(\mathrm{T})$, i.e. the data showed no clear fractal behaviour after meditation. 
One could even suggest that the data were shifted toward a more random behaviour after meditation. In fact, this result is counter-intuitive, as one would rather expect an ordering influence of the process of meditation. Further research is needed to clarify this issue.

It is of interest in future research to characterise the influence of blood flow and breathing dynamics in meditation on the statistics of UPE. We cannot exclude that some of our specu- lations will have to be modified after further experimentation. Yet, we believe that this work deserves to be followed up.

\section{Acknowledgements}

This work was supported by the Samueli Institute of Information Biology, the Rockefeller-Samueli Center for Research in Mind-Body Energy, the Fred Foundation, and the Foundation for Bioregulation Research.

\section{References}

1 Shapiro DH: Clinical and physiological comparison of meditation with other self-control strategies. Am J Psychiatry 1982;139:267-274.

2 Engel K: Meditation. Geschichte, Systematik, Forschung, Theorie, Frankfurt/M., Peter Lang, 1995.

- 3 Wallace RK: Physiological effects of transcendental Meditation. Science 1970;167:1751-1754.

4 Davidson R, Kabat-Zinn J, Schumacher J, Rosenkranz M, Muller D, Santorelli S, Urbanowski F, Harrington A, Bonus K, Sheridan J: Alterations in brain and immune function produced by mindfulness meditation. Psychosom Med 2003;65:564-570.

5 Petermann F, Vaitl D: Handbuch der Entspannungsverfahren, Bd 2. Anwendungen. Weinheim, Psychologie Verlags Union, 1994.

6 Majumdar M: Meditation und Gesundheit: Eine Beobachtungsstudie. Essen, KVC Verlag, 2000.

7 Schneider RH, Nidich SI, Salerno JW, Sharma HM, Robinson CE, Nidich RJ, Alexander CN: Lower lipid peroxide levels in practitioners of the transcendental meditation program. Psychosom Med 1999;60:38-41.

8 Van Wijk R, Van Wijk EPA: An introduction to human photon emission. Forsch Komplementärmed Klass Naturheilkd DOI: 10.1159/000083763.

9 Van Wijk EPA, Van Wijk R: Multi-site recording and spectral analysis spontaneous photon emission from human body. Forsch Komplementärmed Klass Naturheilkd DOI: 10.1159/000083935.
10 Dobrin R, Kirsch C, Kirsch S, Pierrakos J, Schwartz E, Wolff T, Zeira Y: Experimental measurements of the human energy field; in Krippner S, Rubin D (eds): The Energies of Consciousness. New York, Gordon and Breach, 1975.

11 Dobrin R, Kirsch C, Kirsch S, Pierrakos J, Schwartz E, Wolff T, Zeira Y: Experimental measurements of the human energy field; in Krippner S (ed): Psychoenergetic Systems: The Interface of Consciousness, Energy and Matter. New York, Gordon and Breach, 1979, pp 227-230.

12 Nakamura H, Kokubo H, Parkhomtchouk DV, Chen W, Tanaka M, Zhang T, Kokado T, Yamomoto M, Fukuda N: Biophoton and temperature changes of human hand during Qigong. J Soc Life Information Sci 2000;18:418-422.

13 Vekaria M: Biophoton Emission and Intentionality, Ph. D. dissertation. Californian Institute for Human Science, Encinitas, 2003.

14 Teich MC: Fractal character of the auditory neural spike train. IEEE Trans Biomed Eng 1989;36: 150-160.

15 Teich MC: Fractal neuronal firing patterns; in McKenna T, Davis J, Zormetser SR (eds): Single Neuron Computation. Boston, Academic Press, 1992, pp 589-625.

16 Bassingthwaighte JB, Liebovitch LS, West BJ: Fractal Physiology. New York, Oxford University Press, 1994.
17 Kobayashi M, Devaraj B, Inaba H: Observation of super-Poisson statistics of bacterial (Photobacterium phosphoreum) bioluminescence during the early stage of cell proliferation. Phys Rev E 1998; 57:2129-2133.

18 Van Wijk R, Schamhart DHJ: Regulatory aspects of low intensity photon emission. Experientia 1988; 44:586-593.

19 Van Wijk R, Tilbury RN, Slawinski J, Ezzahir A, Godlewski M, Kwiecinska T, Rajfur Z, Sitko D, Wierzuchowska D, Kochel B, Gu Q, Popp FA, Lilius EM, Marnila P, Van Wijk R, Van Aken JM: Biophoton emission, stress and disease. Experientia 1992;48:1029-1102.

20 Torghele K, Schwabl H, Lipp B, Klima H: Elektromagnetische Bioinformation - eine Übersicht. Forsch Komplementärmed 1995;2:133-144.

21 Sies H: Oxidative Stress: Oxidants and Antioxidants. New York, Academic Press, 1991.

22 Lewis CD, Gebber GL, Larsen PD, Barman SM: Long-term correlations in the spike trains of medullary sympathetic neurons. J Neurophysiol 2001;85:1614-1622.

23 Gebber GL, Zhong S, Lewis C, Barman SM: Differential patterns of spinal sympathetic outflow involving a 10-Hz rhythm. J Neurophysiol 1999;89: 833-840. 